\title{
Exploring pathways for sustainable water management in river deltas in a changing environment
}

\author{
Marjolijn Haasnoot • Hans Middelkoop • \\ Astrid Offermans • Eelco van Beek • \\ Willem P. A. van Deursen
}

Received: 27 July 2010 / Accepted: 8 March 2012 / Published online: 24 March 2012

(C) The Author(s) 2012. This article is published with open access at Springerlink.com

\begin{abstract}
Exploring adaptation pathways into an uncertain future can support decisionmaking in achieving sustainable water management in a changing environment. Our objective is to develop and test a method to identify such pathways by including dynamics from natural variability and the interaction between the water system and society. Present planning studies on long-term water management often use a few plausible futures for one or two projection years, ignoring the dynamic aspect of adaptation through the interaction between the water system and society. Our approach is to explore pathways using multiple realisations of transient scenarios with an Integrated Assessment Meta Model (IAMM). This paper presents the first application of the method using a hypothetical case study. The case study shows how to explore and evaluate adaptation pathways. With the pathways it is possible
\end{abstract}

Electronic supplementary material The online version of this article

(doi:10.1007/s10584-012-0444-2) contains supplementary material, which is available to authorized users.

M. Haasnoot $(\varangle) \cdot$ E. van Beek

Deltares, P.O. Box 177, 2600 MH Delft, The Netherlands

e-mail: marjolijn.haasnoot@deltares.nl

M. Haasnoot · H. Middelkoop

Department of Physical Geography, Utrecht University, P.O. Box 80115,

3508 TC Utrecht, The Netherlands

M. Haasnoot · E. van Beek

Department of Water Engineering and Management, University of Twente, P.O. Box 217, 7500 AE Enschede, The Netherlands

\section{A. Offermans}

International Centre for Integrated Assessment and Sustainable Development (ICIS), P.O. Box 616, 6200 MD Maastricht, The Netherlands

W. P. A. van Deursen

Carthago Consultancy, Oostzeedijk Beneden 23a, 3062 VK Rotterdam, The Netherlands 
to identify opportunities, threats, timing and sequence of policy options, which can be used by policymakers to develop water management roadmaps into the future. By including the dynamics between the water system and society, the influence of uncertainties in both systems becomes clearer. The results show, among others, that climate variability rather than climate change appears to be important for taking decisions in water management.

\section{Introduction}

Water management is essential for living in river deltas. Population growth and potential climate change are increasing pressure on water management. The problem is that we do not know how the future will unfold. Despite this uncertainty decisions need to be taken, because impacts may be significant and the implementation of policies takes time. Also, some strategies may be feasible today but not in the future (in particular those that involve spatial planning). Traditionally, water managers tend to use 'best estimates' of the future based on central estimates of climate change and extrapolations of current socio-economic and water system trends. This wrongly implies that we can predict the future. Such an approach might be feasible for well-understood problems, but not for complex problems with deep uncertainty (Lempert and Schlesinger 2000), such as long-term water management under changing conditions.

Several approaches for decisionmaking under deep uncertainty have been developed. Scenario analysis aims to assess possible impacts and to design and test strategies under different hypothetical futures (e.g. Van der Heijden 1996; Carter et al. 2007). Analysts use simulation models to quantitatively explore the future (e.g. Morgan and Dowlatabadi 1996; Rotmans and De Vries 1997; Van Asselt 2000). Within this emerging school of computational scenario-based approaches it is common to use a limited set of scenarios for one or two projection years to define robust strategies; strategies that are insensitive to uncertainty (e.g. Middelkoop et al. 2004; Van Asselt and Rotmans 2002). Besides robust strategies to either shape the future or to reduce vulnerability to uncertain developments, Dewar et al. (1993) used signposts to monitor the need for changes. This was a first step towards dynamic policymaking. In contrast to static policies, the approach of adaptive policymaking results in contingency plans and specified conditions, called signposts and triggers, under which the policy should be reconsidered (Walker et al. 2001). The concept of adaptive management also involves the ability to change policy practices based on new experience and insights (Pahl-Wostl 2007). Instead of analysing impacts of pressures, Kwadijk et al. (2010) start at the other end of the cause-effect chain by assessing the system's vulnerability, which they then use to determine adaptation tipping points (ATP). These are points at which the magnitude of change is such that the current management strategy can no longer meet its objectives. When this point occurs depends on the scenario. Exploratory modelling uses computational experiments to explore uncertainties in both context and model (Bankes 1993; Agusdinata 2008; Kwakkel et al. 2010). Lempert and Schlesinger (2000), for example, used exploratory modelling for creating a large ensemble of plausible future scenarios to find robust strategies for dealing with climate change. In the field of economics, 
Winkler et al. (2010) propose a conceptual framework (a hybrid of dynamic and static modelling) for climate change assessments of international market systems that involve long-term investments.

In recent papers, we presented a method for exploring adaptation pathways for sustainable water management in river deltas under uncertainty (Haasnoot et al. 2011; Offermans et al. 2011). Adaptation pathways describe a sequence of water management policies enabling policymakers to explore options for adapting to changing environmental and societal conditions. Our approach comprises the use of an Integrated Assessment Meta Model (IAMM) to explore transient scenarios and can thus be considered as a member of the computational scenario-based approaches. While current scenario studies often consider (semi-)static situations in terms of a few plausible futures projected forward to one or two future years, we acknowledge pathways towards the endpoint by including dynamics from natural variability and the interaction between the water system and society. In the course of time, events may trigger policy responses and may change societal perspectives, including the interests and evaluation of strategies (see for historical examples Van der Brugge et al. 2005; Offermans 2010). Adaptation over the course of time thus depends on the evolution of the pathway. The end point is therefore not only determined by what is known or anticipated at present, but also by what will be experienced and learned when the future unfolds (Yohe 1990), and by the policy responses to events. Thus, policymaking becomes part of the storyline, and thereby an essential component of the total uncertainty. With an adaptation map-a set of adaptation pathways-resulting from these analyses it is possible to identify opportunities, no-regret strategies, dead ends, and timing of a strategy, all of which can be used by policymakers to develop water management roadmaps into the future.

As most existing computational impact models (for example Vermulst et al. 1998; Delsman et al. 2008) demand too much computing time for simulating the dynamics of adaptation pathways, we have developed an IAMM based on these complex detailed models. Such metamodels are also referred to as 'low-resolution models' (Davis and Bigelow 1998) or 'Fast Simple Models' (Van Grol et al. 2006). The concept of Integrated Assessment Models (IAMs) has been successfully applied on a global scale to analyse climate change and the effects of emission mitigation strategies (e.g. Rotmans and Van Asselt 1996; Van der Sluijs 2002; Schneider and Lane 2005; Van Vuuren et al. 2011). In our study we apply the concept of IAMs for impact assessment and adaptation analysis in combination with transient scenarios and social response on a regional to local scale.

The objectives of the study presented here were to implement the method of exploring adaptation pathways in a case study and to evaluate the implementation and use of the results. The key questions addressed were: Can we establish simple though realistic cause-effect relations as building blocks of the IAMM? Does the IAMM yield plausible results? How can we establish storylines, and how do these evolve? How do we evaluate these storylines and what kind of decisions on water management can we make? To answer these questions we set up a modelling experiment for a hypothetical case inspired by a real-world river reach in the Netherlands. With the developed IAMM, we carried out numerous transient runs driven by different realisations of future climate, and analysed different water policy options as an adaptation pathway in each run, which we then summarised into an 
adaptation map. We evaluated the performance of the policy options and pathways according to three perspectives.

\section{Method}

Our method consists of a conceptual framework and a technological framework, which are elaborated in Haasnoot et al. (2011) and Offermans et al. (2011). This section briefly describes the method.

\subsection{Conceptual framework}

Three concepts are the pillars of our approach: (1) the Pressure State Impact Response (PSIR) concept (OECD 1993; Rotmans and De Vries 1997; Hoekstra 1998), describing interactions between the water and social system; (2) the Perspectives method, describing people's dynamic view on the value of water and how water should be managed; and (3) transient scenarios, describing possible futures in terms of time series (Haasnoot et al. 2011).

The PSIR concept applied to water management can be illustrated by the following example: climate change and population growth (pressures) may decrease fresh water availability and increase the water demand (state), resulting in less drinking water and agricultural damage (impact), which may then cause a management response in terms of water storage in large basins (response) in order to supply water in the case of scarcity (state). Instead of the common linear use of the PSIR concept, we use it in an iterative process and proceed in cycles per time step (as suggested by Pahl-Wostl (2007)) and elaborate the response part by distinguishing between water policy and autonomous stakeholders' response (Offermans et al. 2011).

The Perspectives method is based on the Cultural Theory (Douglas 1970; Thompson et al. 1990) and developed by the TARGETS research group (Van Asselt and Rotmans 1997). A Perspective is a consistent description of the perceptual screen through which people interpret the world, and which guides them in acting and dealing with uncertainties. Applied to water, three active stereotypical perspectives, each with a different expectation about the future and a preferred strategy can be distinguished (Hoekstra 1998; Middelkoop et al. 2004; Offermans et al. 2011): The Hierarchist believes in controlling water and nature, assigning major responsibilities to the government. Water is mainly seen as a threat to human safety, resulting in a preference for water policy options such as building and raising dikes and channelling, while leaving space for some economic and natural development. The Egalitarian focuses on the environment and equity, resulting in strategies such as room for the river, decreasing human demands, and relocation to higher areas. The Individualist adheres to a liberal market and a high trust in technology and innovation. Their preferred water management policies focus on cost effective and innovative projects, such as living on water and building offshore islands.

Transient scenarios describe possible futures from today to a point in the future, including changing conditions from a sequence of developments and events. We distinguish between (1) transient scenarios of external context that describe only the 
pressures (e.g. changing climate), and (2) complete transient scenarios, which are storylines including all the elements of the PSIR chain, including natural and socioeconomic events (e.g. floods, droughts, economic crisis), trends (e.g. climate change, changing public perception of safety or nature), and interactions between the water system and society (e.g. flood impacts, flood mitigation strategies).

A simulation starts with a description of the past and current system state and possible and desired futures according to different Perspectives. Depending on the evaluation of the past and the expectations of the future, policies are adopted and strategies implemented. In each run of the IAMM, a year-by-year evolution of the whole PSIR chain occurs. For example, a climate realisation with corresponding precipitation results in a sequence of peak river discharges and associated impacts; strategies may then be implemented accordingly. In addition to events in the water system, societal events may occur. We interpret these events as external context, and include these as random components. Such societal events may well lead to changes in management, for example when budgets are reduced. Besides this responsive management, strategies may also be chosen in view of anticipated impacts (depending on the prevailing Perspective). Moreover, even a change in Perspectives may occur. For example, climate-related events may increase the awareness of potential climate change, or the absence of such events may decrease support for the implementation of strategies. Water management history in the Netherlands has shown, for example, that an accumulation of events caused the dominant Hierarchical perspective to become more Egalitarian (Offermans 2010). The most important events contributing to this shift were the fire in the Sandoz factory (1986) causing all the fish in a radius of $100 \mathrm{~km}$ to die, the Endosulfan poisoning of the Rhine (1969), and an increased visibility of water quality problems (i.e. foam, smelling water, dying fish). Besides these water quality related events, the Chernobyl disaster, a growing societal attention for environment and peace (Flower Power) and publications such as 'Silent Spring' and 'Limits to Growth' contributed to a move from Hierarchism towards Egalitarism. Management responses can be a priori entered into the IAMM through response rules, or can be derived from single or multiple users of the model, such as policymakers in a game setting. A single storyline is completed when the river has been managed for 100 years. Different pathways into the future arise from different climate scenarios, different realisations of the same climate scenario, external socioeconomic events or trends, and due to different management responses during a scenario run. This set of different pathways represents the uncertainty for water management into the future.

We evaluate the policy options on their performance in each storyline using indicators for a sustainable strategy. The weights given to these indicators will generally differ for each Perspective. We first analyse the effects of individual strategies for all transient scenarios (all realisations of the scenarios) and for each scenario separately. These results are then used to determine the durability of a strategy, indicating under what conditions the strategy may fail to meet the objectives (reaching an adaptation tipping point (ATP)), and at what point in the future this may happen under each scenario and for each Perspective. We refer to this as the sell-by date of a policy option, which is the moment when an ATP is reached. By exploring all the relevant policy options after an ATP with a computational model, we established different pathways, which we then analysed on their performance according to targets (weights 
to the indicators) (Fig. 1). The final adaptation map, manually drawn based on all the model results, presents the relevant pathways (e.g. it is not logical to establish houses on a mound and also make them able to float in case of a flood).

\subsection{Technological framework}

The PSIR cycle is modelled using the IAMM in a number of transient scenarios with different responses to develop storylines. We designed the IAMM such that it fulfilled the following requirements: It must run fast enough to calculate 100year transient scenarios when used interactively or participatorily in a game-like setting. Secondly, the IAMM should represent the dominant processes and natural variability but without unnecessary detail (as suggested by Booij 2003). Finally, it should be able to implement individual policy options, reflecting a wide range of Perspectives in such a way that users can choose the preferred management response. The outcomes from the model should be such that users can understand them, and that the performance of strategies should be quantified by relevant indicators, which are measures of sustainability.

We used the technique of metamodelling to enable exploring many transient scenarios and management responses. Metamodels, or models of models, are simple aggregated models that approximate the behaviour of models that are more complex and detailed (Davis and Bigelow 1998, 2003). They can be obtained purely statistically, also known as response surfaces (Kleijnen and Sargent 2000), or theorymotivated, using physical and behavioural reasoning to determine the structure of the model and statistical analysis to determine the coefficients (Bigelow and Davis 2003). This study's model is built up by a set of small metamodels describing parts of the cause-effect chain, which are then fully integrated. This idea of developing the IAMM in terms of cause-effect relations is derived from existing habitat analysis models (e.g. Guisan and Zimmermann 2000) describing the relation between the potential occurrence of species and environmental conditions. Haasnoot and
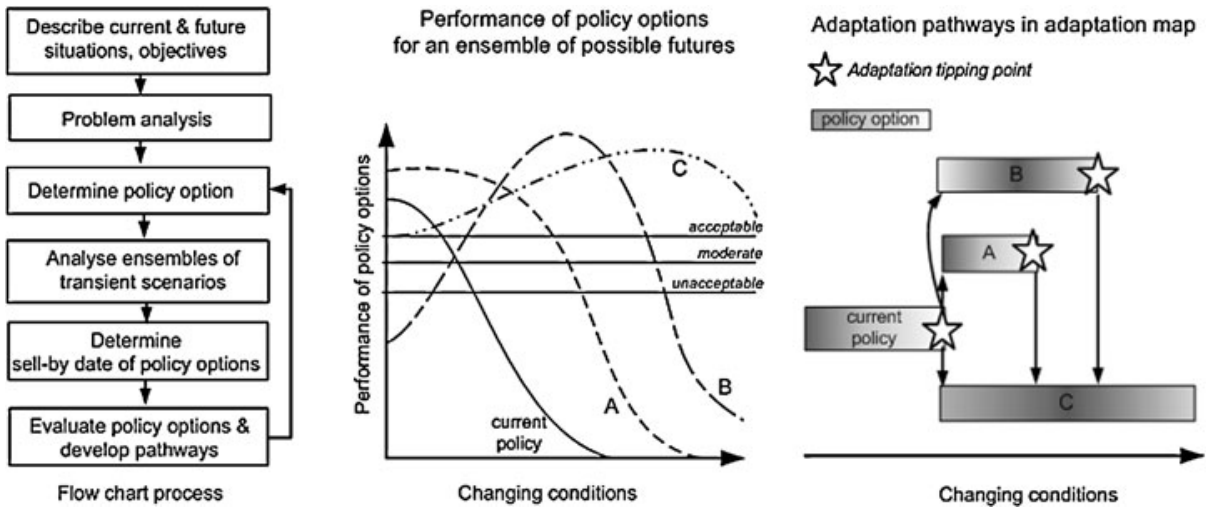

Fig. 1 The construction of adaptation pathways is based on the performance of individual policy options $(A, B, C)$ for an ensemble of possible futures. After an adaptation tipping point, the point at which a strategy fails to meet its objectives, all policy options are considered. Individual policy options are identified based on objectives and current and expected vulnerabilities 
Van der Wolfshaar (2009) extended this with physical cause-effect relations describing the effects of policies on the environmental conditions.

The core of the IAMM comprises (1) metamodels describing cause-effect relations of the physical system, and (2) a response base describing the perspective dynamics and (changes in) management style in response to states, impacts, or societal events. The cause-effect relations relate the climate and socio-economic pressures to changes in the state of the hydrological system (e.g. precipitation and discharges, water levels) and social system (e.g. land use), and describe the impacts on the different waterrelated sectors (Fig. 2). The metamodels are based on (the results of) complex hydrological and impact models applied in previous studies. The response rules for the hypothetical case are simple if-then relations, like: 'if $\mathrm{x}$ occurs in the water system then strategy y is implemented'.

\section{Implementing the method in a hypothetical case study}

\subsection{Study area: the Waas case study}

The hypothetical case study, called the Waas, is inspired by a river reach in the Rhine delta of the Netherlands (the river Waal). The river and floodplain are highly schematised, but have realistic characteristics. The river is bound by embankments, and the floodplain is separated into five dike rings (Fig. 3). A large city is situated on higher grounds in the south-east part. Smaller villages exist in the remaining area, including greenhouses, industry, conservation areas, and pastures.

A scenario run starts on the basis of a 'report' of the assumed past 25-year history, in which the following occurred: There were two flood events, which flooded four dike rings in total. The total damage over the past 25 years was 2,810 billion Euros. On average, water levels were too low to allow navigation over 29 days per year

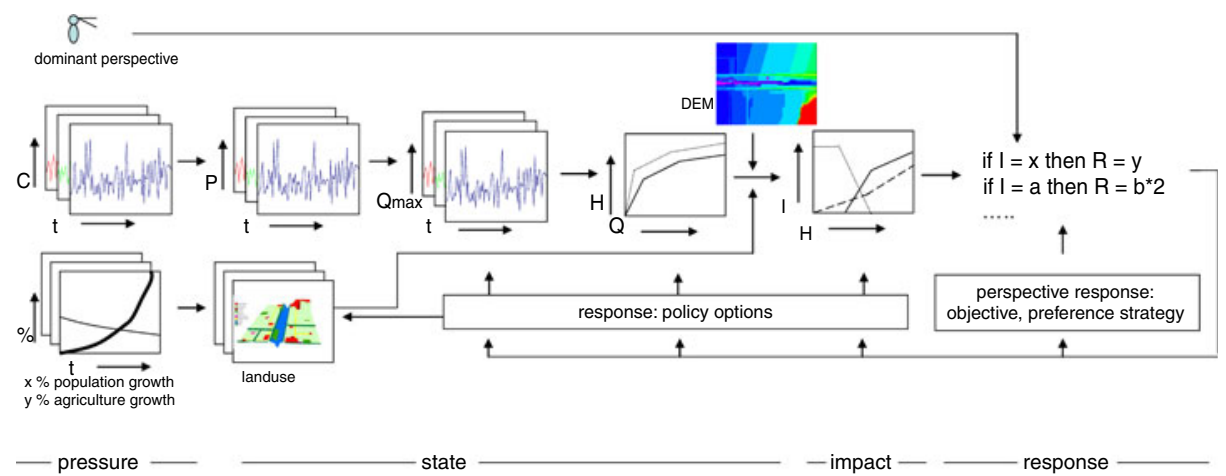

Fig. 2 Schematisation of cause-effect relations and response functions in the IAMM. Climate realisations $(C)$ are translated into precipitation $(P)$, which are translated into discharges $(Q)$ at the upstream boundary of the study area. Water level-discharge $(H-Q)$ relations are used to derive water levels along the river. The resulting water levels are translated into an impact $(I)$ using an elevation map and effect functions. Socio-economic realisations, such as population dynamics and agriculture area, are translated into land use. Management and perspective response functions relate impacts to strategies by means of input maps and effect functions 

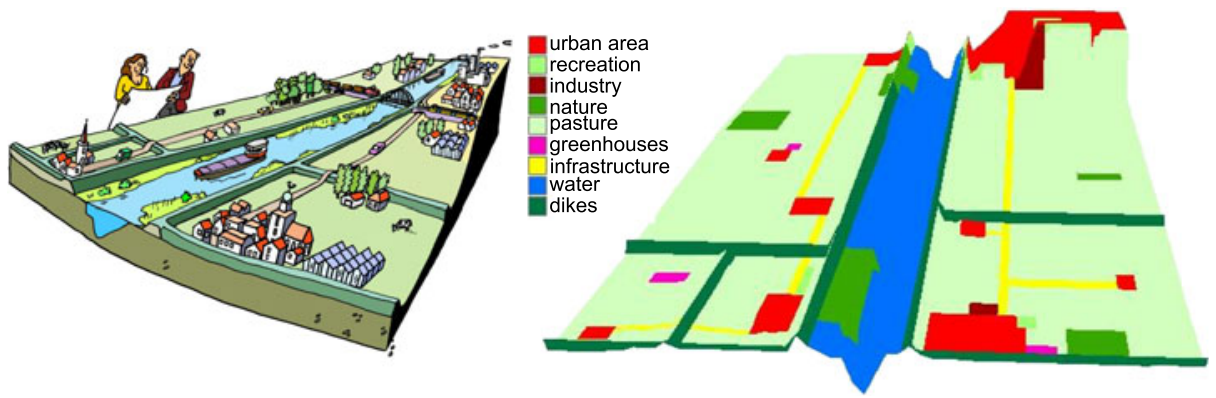

Fig. 3 The Waas case study (left) is heavily schematised (right) into a three-dimensional image of the floodplain presenting the land use and elevations (exaggerated vertically). The flow direction is from back to front

(navigable time was $92 \%$ ). The Waas population considered the first flood event as a matter of bad luck that could be prevented in the future by means of control- and engineering policies. After the second flood, people realised that climate change may have an influence, and that a control approach may not be sufficient to guarantee safety in the long run. Consequently, the citizens adopted a Hierarchical Perspective with some elements of the Egalitarian Perspective: the preferred strategies aim at controlling the system (Hierarchical). However, for the long-term they envision spatial solutions for dealing with increased peak discharges caused by climate change, which corresponds with an Egalitarian approach. The past flood and drought events demonstrate that the system has not been adequately managed. In the future, climate change and socio-economic developments may increase the pressure on the available space and potential future damages, so additional strategies are needed.

At the starting point policies can be taken to improve the state of the system such that future adverse impacts are reduced or prevented. Then the future starts to unfold in which events occur and additional policies can be implemented in each time step. To evaluate the performance of the individual policy options, indicators were used for the three pillars of sustainability: people, profit, and planet. The value ranges for the indicators (the targets) are based on the prevailing Perspective. The values given in Table 1 are those associated with the Hierarchist Perspective. The Egalitarian gives a more weight to the planet indicators than the Hierarchist and accepts a larger amount of floods and non-navigable time. The Individualist gives a more weight to navigation and flood damage than the Hierarchist. For the development of the pathways we used two indicators, which reflect the most important impacts for decisionmaking. The indicator 'flood damage' was used for the flood management pathways and the 'percentage of non-navigable time' for the low flow pathways. To consider the potential effects of different Perspectives or changes in Perspective, the targets were set two times larger for the Egalitarian and two times smaller for the Individualist.

\subsection{Transient climate scenarios}

Three climate scenarios established by the Royal Dutch Meteorological Institute (KNMI) were considered: no climate change, G scenario, and Wp scenario (Van den Hurk et al. 2007). These scenarios cover a range of possible future climates in 
Table 1 Indicators and their limits per 25 years for the Hierarchist perspective

\begin{tabular}{clccl}
\hline & & Acceptable & Moderate & Unacceptable \\
\hline People & Number of missed floods/year & 0 & $0-5$ & $>5$ \\
indicators & Urban area flooded $\mathrm{km}^{2} / \mathrm{yr}$ & $<0.2$ & $0.2-0.5$ & $>0.5$ \\
& Number of dike rings flooded/yr & 0 & $1-2$ & $>2$ \\
& Number of false alarms/yr & $<1$ & $1-2$ & $>2$ \\
Profit & Total flood damage $(\mathrm{M}$ euro/year) & $<150$ & $150-1000$ & $>1000$ \\
indicators & Agricultural flood damage $(\mathrm{M}$ euro/yr) & $<20$ & $20-50$ & $>50$ \\
& Average non-navigable time $(\%)$ & $<2$ & $2-7$ & $>7$ \\
Planet & Nature area $\left(\mathrm{km}^{2}\right)$ & $>14$ & $12-14$ & $<12$ \\
indicators & Diversity index ecology & $>0.5$ & $0.4-0.5$ & $<0.4$ \\
\hline
\end{tabular}

The limits are based on the average of occurrence per 25 years. The values in the column 'acceptable' can be considered as possible targets for policymakers in a Hierarchical world. Missed floods are floods without an alarm. The false alarms are events with an alarm without an actual subsequent flood occurrence. The 'diversity index for ecology' indicates the diversity of the potential vegetation types in the area and ranges from 0 to 1

the Netherlands. The $\mathrm{G}$ scenario has a temperature rise of $1^{\circ} \mathrm{C}$ in 2100 , the wintertime precipitation increasing by $3.6 \%$ and the mean summer precipitation increasing by $2.8 \%$. The $\mathrm{Wp}$ scenario has a temperature rise of $2^{\circ} \mathrm{C}$, winter-time precipitation increasing by $14.2 \%$, but the mean summer-time precipitation decreasing by $19 \%$.

The transient climate scenarios are based on simulations using the KNMI Rainfall Generator (Buishand and Brandsma 1996). The Rainfall Generator gives an ensemble of 100 years of precipitation and evaporation data based on the probability of events. With the delta change approach (Lenderink et al. 2007; Te Linde 2007), these series were translated into time series for each climate change scenario (which are assumed to change linearly up to the year 2100). The precipitation and evaporation time series for the scenarios were then used in a hydrological model for the Rhine (Te Linde et al. 2010) to produce discharge data for the Rhine at Lobith, which are the upstream boundary conditions for the IAMM. For each of the three climate scenarios, ten realisations of precipitation and evaporation events were considered for the next 100 years, resulting in 30 transient climate scenarios in total. The transient scenarios of climate-driven discharges include the maximum river discharge per year, the number of days per year at which ecologically-sound discharges are exceeded and the number of days per year that discharge is lower than several relevant discharges for shipping. Figure 4 gives an example of five of the transient scenarios used. The figure shows that the year to year variation is large, in comparison to the climate change trend.

\subsection{Implementation of cause-effect relations}

Figure 5 gives a schematic presentation of the cause-effect relations incorporated in the IAMM for the Waas case. These relations were all derived from validated models for an area similar to the hypothetical case. We implemented the IAMM and its cause-effect relations using PCRaster, a grid-based spatial analysis tool for dynamic modelling (Van Deursen 1995). The IAMM was checked for internal consistency and plausibility of the outcomes by expert judgement. Supplementary Appendix shows the most relevant cause-effect relations. Discharges arising from the transient climate scenarios were translated into water levels using stage-discharge relations for each 


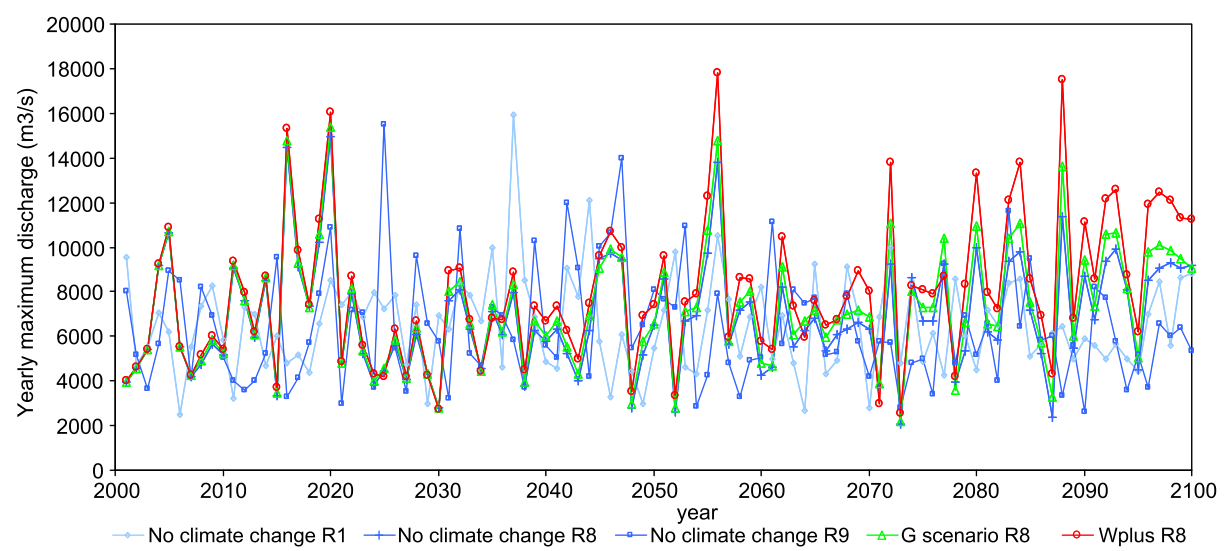

Fig. 4 Transient scenarios for five realisations: three realisations of a scenario without climate change, one realisation for climate change scenario $G$, and one realisation for scenario $W p$

grid cell along the river Waas. These relations were derived from modelling results using a 1D hydrodynamic model (SOBEK) for the river Waal in the Netherlands. The water levels were translated into a $2 \mathrm{D}$ surface, and were compared with the dike heights derived from the elevation map. Subsequently, the model calculated the probability of dike failure caused by piping or by wave overtopping by examining the difference between dike level and water level (Van Velzen 2008). Whether the dike fails or not depends on a random number selected between 0 and 1 . If that number is lower than the probability of dike failure, the dike is assumed to fail, even if the water does not overtop it. In the case of a dike failure, the water level was considered to be equal to the river water level in the whole dike ring. Damage due to the flooding of dike rings was calculated from the water depth, derived from the water level and

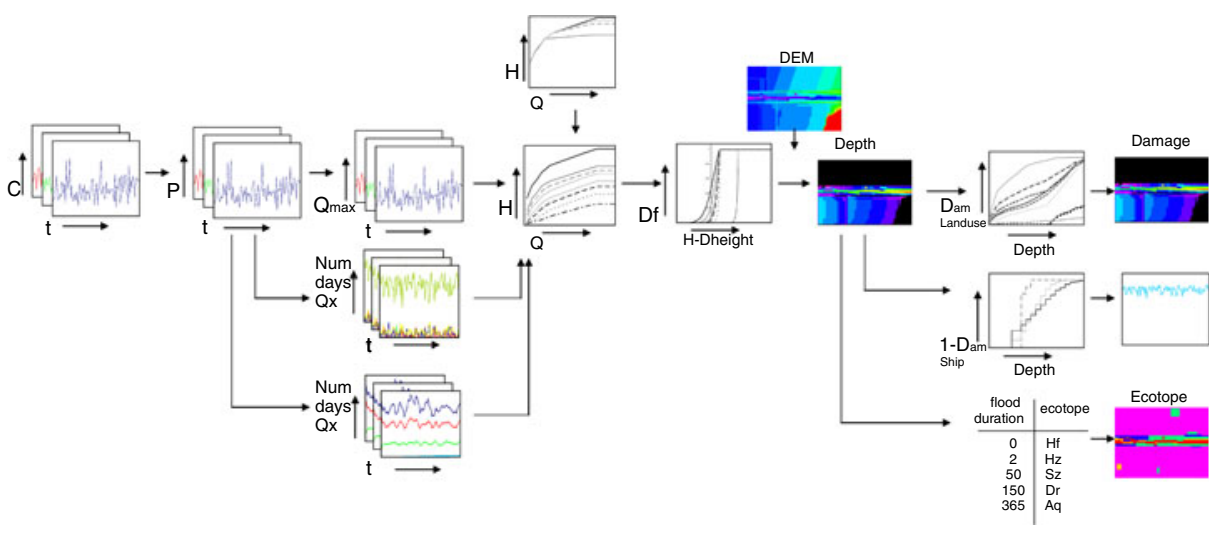

Fig. 5 Schematisation of cause-effect relations incorporated in the IAMM for the Waas case. C= climate realisation, $\mathrm{P}=$ precipitation surplus, $\mathrm{Qmax}=$ maximum discharge, Num days $\mathrm{Qx}=$ number of days exceeding of lower discharges for discharges relevant for ecology or navigation, $\mathrm{Df}=$ chance of dike failure, Dheight = dike height, Dam = damage, Ecotope = ecozones, $\mathrm{H}=$ water level. The most relevant cause-effect relations are given in detail in Supplementary Appendix 
a digital elevation map (DEM), and damage relations for the Netherlands given in (De Bruijn 2008; Haasnoot et al. 2009). Using these relations, the model calculates, for each land use, the flood impacts per hectare, by multiplying the maximum potential flood damage in the cell under consideration by this water level-dependent damage factor (value between 0 and 1 ). The maximum potential damage and the shape of the damage curves were derived from the HISSM model (Kok 2005). This yielded the total damage for sectors such as agriculture, industry, and housing.

Cause-effect relations for shipping, describing the water depth and the suitability for shipping were derived from the SHIPS@RISK model, which was developed in a previous study to determine the effects of low flows on transport cost by inland navigation over the Waal-Rhine rivers between Rotterdam harbour and the Ruhr hinterland (Middelkoop and Van Deursen 1999). The suitability is expressed by a value between 0 and 1 (i.e. the fraction of total time that navigation is possible) and differs per type of vessel. For each relevant discharge $(400,600,800,1,000$, and $12,000 \mathrm{~m}^{3} / \mathrm{s}$ ) the number of days with a lower discharge is multiplied by the suitability and then summed over all discharges, resulting in the total proportion of navigable time $(\%)$.

To model the impact on ecology, ecologically-relevant flood durations $(2,50,150$, and 365 days/year) were used to distinguish different ecozones with different riparian vegetation types (Haasnoot and Van Der Molen 2005). From dry to wet areas, the following ecozones were distinguished: high water free zones ( $<2$ days/year), hardwood zones (2-50 days/year), softwood zones (50-150 days/year), drying zones (150-364 days/year), water with macrophytes (always under shallow water) and water without macrophytes (always under water, deeper than $3 \mathrm{~m}$ ). The effect on each ecozone was transformed into an diversity index for ecology by multiplying the relative area by a weighting factor. The sum of these weighted areas is then scaled to an index between 0 and 1. The weighting factor is six for the rarest zone and one for the most common zone.

\subsection{Identification of policy options}

Policy options were based on existing plans and potential strategies for flood management, nature development, and navigation (low flow management) in the Netherlands (Table 2). To ensure a diverse range of policy options, we related the strategies to the Perspectives and added strategies (if available) in the case a Perspective was under-represented. The options were implemented in the IAMM by changing input maps (e.g. dike height or position), adapting the cause-effect relations (e.g. stage-discharge relation, damage function), or changing the river inflow (resulting from successful cooperation with upstream regions).

\subsection{Simulations and development of adaptation pathways}

Numerous simulation runs were executed for different (combinations of) policy options and realisations of transient climate scenarios. The result of each run is a time series with the evolution of performance indicators, and the sum for each performance indicator for each period of 25 years and for the total 100 years. Also, the total costs of the actions implemented during a scenario run were calculated. 
Table 2 Description of the individual policy options and their total costs for the next 100 year and purposes

\begin{tabular}{|c|c|c|c|}
\hline Abbreviation & Description & $\begin{array}{l}\text { Cost } \\
\text { (Meuro) }\end{array}$ & Purpose \\
\hline DH500 & $\begin{array}{l}\text { Dike height rise to be able to cope } \\
\text { with the 1:500 discharge, based } \\
\text { on measurements }\end{array}$ & $112 * *$ & Flood risk \\
\hline DH1000 & $\begin{array}{l}\text { Dike height rise to be able to cope } \\
\text { with the } 1: 1000 \text { discharge, based } \\
\text { on measurements }\end{array}$ & $142 * *$ & Flood risk \\
\hline DH1.5 & $\begin{array}{l}\text { Dike rise: adapting to } 1.5 \text { times } \\
\text { the second highest discharge ever } \\
\text { measured ('rule of thumb measure') }\end{array}$ & $228 * *$ & Flood risk \\
\hline RfRl & $\begin{array}{l}\text { 'Room for the river'-Large scale: } \\
\text { with extra side channels, the river } \\
\text { has more space after a threshold } \\
\text { discharge is exceeded }\end{array}$ & 269 & $\begin{array}{l}\text { Flood risk } \\
\& \text { nature }\end{array}$ \\
\hline RfRs & $\begin{array}{l}\text { 'Room for the river'-Small scale: } \\
\text { with extra side channels, the river } \\
\text { has more space after a threshold } \\
\text { discharge is exceeded }\end{array}$ & 138 & $\begin{array}{l}\text { Flood risk } \\
\& \text { nature }\end{array}$ \\
\hline CopU & $\begin{array}{l}\text { Upstream cooperation: discharges } \\
\text { are reduced to } 14.000 \mathrm{~m}^{3} / \mathrm{s}\end{array}$ & 0.03 & Flood risk \\
\hline FloatH & $\begin{array}{l}\text { Floating houses: resulting in damage } \\
\text { functions with ten times less damage }\end{array}$ & 6 & Flood risk \\
\hline $\mathrm{FaC}$ & $\begin{array}{l}\text { Fort cities: extra embankments } \\
\text { around the cities }\end{array}$ & $550-660$ & Flood risk \\
\hline Mound & $\begin{array}{l}\text { All cities will be raised by } 4 \mathrm{~m} \text { in the } \\
\text { DEM, resulting in houses on a area } \\
\text { of elevated ground }\end{array}$ & 1006 & Flood risk \\
\hline Smalls & $\begin{array}{l}\text { Use small ships* ( } 300 \text { ton) to ensure } \\
\text { navigation at low discharges }\end{array}$ & 40 & $\begin{array}{l}\text { Navigation } \\
\quad \text { (low flow) }\end{array}$ \\
\hline MediumS & $\begin{array}{l}\text { Use medium size ships* ( } 3,000 \text { ton) } \\
\text { to ensure navigation at low discharges }\end{array}$ & 40 & $\begin{array}{l}\text { Navigation } \\
\text { (low flow) }\end{array}$ \\
\hline SmallD & $\begin{array}{l}\text { Small-scale dredging of the riverbed } \\
\text { to ensure larger ships can keep } \\
\text { navigating at lower discharges }\end{array}$ & $0.015-0.02$ & $\begin{array}{l}\text { Navigation } \\
\text { (low flow) }\end{array}$ \\
\hline LargeD & $\begin{array}{l}\text { Large-scale dredging of the riverbed } \\
\text { to ensure larger ships can keep } \\
\text { navigating at lower discharges }\end{array}$ & $0.18-0.22$ & $\begin{array}{l}\text { Navigation } \\
\quad \text { (low flow) }\end{array}$ \\
\hline
\end{tabular}

The costs are based on the situation in the Netherlands (see Supplementary Appendix for an explanation on how the costs were determined)

*In the current situation large ships of 6,000 tons are used

**These costs depend largely on peak discharges and thus the scenario and realisation. In the table the average costs are given

For the evaluation of the policy options, we analysed their robustness by comparing its performance with the ranges for the indicators given in Table 1, and by using the standard deviation of the performance. For each Perspective, different indicator ranges were taken (as described in Section 3.1). We analysed the effects for all transient scenarios (ten realisations of three climate scenarios), for all realisations of each climate scenario separately, and for each 25-year period. 
For the creation of pathways we used perspective-based targets for two indicators. For flood management we considered a limit for the total damage, and for the low flow strategies we used a limit for the non-navigable time. With these targets, we determined the sell-by date of each policy option. Pathways were then generated by using the sell-by date and based on the assumption that, if a policy option no longer meets the targets, it is necessary to add, or to shift to another policy option. Since only two policy options influence nature, nature was only taken into account in the evaluation of the pathways.

\section{Results of the simulations}

\subsection{Evaluation of the robustness of the policy options}

\subsubsection{Flood management policy options}

We first describe the average performance of the policy options for the indicators in a Hierarchist world (Table 1). Robust strategies result in acceptable indicator values under many futures. All flood policy options reduce the impact compared to the reference situation without implementation of policies (Fig. 6). However, the only option for which all of the risk indicators of Table 1 are acceptable is raising the dikes to such an extent that they can cope with 1.5 times the second highest discharge in the past (DH1.5). Raising the dikes to a 1:1000 discharge (DH1000) scores moderately well. Implementing the 'room for the river' on a large scale leads to a slightly larger number of dike rings being flooded, which, according to Table 1 makes this policy option unacceptable for this indicator. Implementing dikes around the cities $(\mathrm{FaC})$ prevents the urban areas from flooding, resulting in the largest improvements compared to the reference case without policies taken.

Upstream cooperation alone is not an effective policy option. It lowers the peak discharge to $14.000 \mathrm{~m}^{3} / \mathrm{s}$, but floods and damage still occur. The dikes around the cities are most effective in reducing inundation of urban areas. The dike-raising options and 'room for the river' are subsequently less effective. Surprisingly, the policy option in which houses are built on artificial mounds does not score much better on this urban area indicator, than the reference situation. Apparently, the mounds are not high enough, although they were established at $4 \mathrm{~m}$ height. Out of the damage mitigation options, the dikes around the cities and floating houses are the most effective. However, the average absolute damage is higher than in the flood mitigation options. Whatever policy options were to be chosen, the costs of the policy options would still be well below the expected damage reduction (Table 2 and Fig. 6).

As a second criterion for the robustness of strategies, the standard deviations of the evaluation criteria obtained for each policy option under all transient scenarios were compared. Robust strategies result in small standard deviations for the indicators, having acceptable indicator values at the same time. The relative performance for each option is similar to the absolute results. Dike-raising and large-scale 'room for the river' appear to be the most robust options, while the damage mitigation options are less robust. The standard deviation of the total damage is high for all policy options; thus, even the most robust strategy can result in large-scale damage.

The policy options were also evaluated for the ten ensemble members of each climate scenario separately (presented in Supplementary Appendix). For all climate 


\begin{tabular}{|c|c|c|c|c|c|c|c|}
\hline & $\begin{array}{l}\text { Dike } \\
\text { rings } \\
\text { flooded } \\
\text { (\#) }\end{array}$ & $\begin{array}{l}\text { Urban } \\
\text { area } \\
\text { flooded } \\
\left(\mathrm{km}^{2}\right)\end{array}$ & $\begin{array}{l}\text { Total damage } \\
\text { (Meuro) }\end{array}$ & $\begin{array}{l}\text { Agricultural } \\
\text { damage } \\
\text { (Meuro) }\end{array}$ & $\begin{array}{l}\text { Non- } \\
\text { navigable } \\
\text { time }(\%)\end{array}$ & $\begin{array}{l}\text { Nature } \\
\text { (ha) }\end{array}$ & $\begin{array}{l}\text { Ip } \\
\text { fac- } \\
\text { tor }\end{array}$ \\
\hline \multicolumn{8}{|c|}{ Flood policy options } \\
\hline No policy & $41 \pm 14$ & $26 \pm 9$ & $27362 \pm 9750$ & $1056 \pm 383$ & & 13 & N/A \\
\hline DH500 & $8 \pm 4$ & $6 \pm 2$ & $5227 \pm 2290$ & $167 \pm 83$ & & 13 & 5 \\
\hline DHI000 & $7 \pm 3$ & $5 \pm 2$ & $4285 \pm 2128$ & $139 \pm 79$ & & 13 & 6 \\
\hline DHI.5 & $2 \pm 2$ & $2 \pm 1$ & $1256 \pm 1274$ & $41 \pm 44$ & & 13 & 19 \\
\hline RfRI & $8 \pm 4$ & $5 \pm 2$ & $4706 \pm 2683$ & $149 \pm 88$ & & 20 & 5 \\
\hline RfRs & $35 \pm 13$ & $20 \pm 7$ & $21767 \pm 8375$ & $748 \pm 298$ & & 17 & 1 \\
\hline CopU & $39 \pm 13$ & $24 \pm 8$ & $26077 \pm 8919$ & $1013 \pm 356$ & & 13 & 1 \\
\hline FloatH & $41 \pm 14$ & $26 \pm 9$ & $8479 \pm 3146$ & $1056 \pm 383$ & & 13 & 2 \\
\hline $\mathrm{FaC}$ & $41 \pm 14$ & $0 \pm 1$ & $6381 \pm 2439$ & $1056 \pm 383$ & & 13 & 26 \\
\hline Mound & $41 \pm 14$ & $20 \pm 7$ & $15837 \pm 6252$ & $1056 \pm 1803$ & & 13 & I \\
\hline \multicolumn{8}{|c|}{ Low flow policy options } \\
\hline No policy & & & & & $8.9 \pm 3.15$ & & N/A \\
\hline SmallS & & & & & $0.2 \pm 0.00$ & & 44 \\
\hline MediumS & & & & & $6.4 \pm 3.58$ & & 1 \\
\hline SmallD & & & & & $0.5 \pm 0.03$ & & 19 \\
\hline LargeD & & & & & $0.3 \pm 0.10$ & & 19 \\
\hline \multicolumn{3}{|c|}{ Hierarchist } & \multicolumn{2}{|c|}{ Egalitarian } & \multicolumn{3}{|c|}{ Individualist } \\
\hline & & & & & & & \\
\hline & & & & & & & \\
\hline \multirow{2}{*}{\multicolumn{8}{|c|}{ 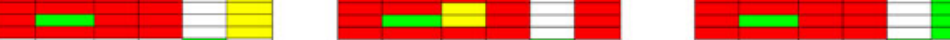 }} \\
\hline & & & & & & & \\
\hline & & & & & & & \\
\hline & & & & & & & \\
\hline
\end{tabular}

Fig. 6 Scorecards with the average performance of all policy options for all ensemble members of all climate scenarios in 100 years. The 'Ip factor' refers to the improvement of the results compared to the reference situation without strategies. For the flood management strategies the average of the indicators is taken. Table 2 gives a description of the policy options. The three tables at the bottom indicate how each perspective evaluates the performance for the indicators. The colours refer to the acceptability categories of Table 1 and indicate whether targets for each perspective are achieved. Green: acceptable results; Yellow: moderate results; Red: unacceptable results

scenarios, the policy options raising the dikes to cope with 1.5 times the second highest discharge (DH1.5) and establishing dikes around the cities (FaC) result in the largest improvements compared to the reference situation. The differences in performance between the realisations without climate change and those for the $G$ climate change scenario are small. This is in contrast to the Wp realisations, wherein none of the policy options leads to the fulfilment of the targets. In this extreme scenario, the dike-raising strategies for the 1:1000 and 1:500 discharges perform better than giving more ' room for the river' on a large scale, which is different from results for all scenarios. This is because the dike-raising options depend on the changing conditions (they adapt over time), while the 'room for the river' options do not change.

Robust strategies are not only dependent on physical conditions, but also on societal conditions, such as a Perspective. In case the current Hierarchist Perspective changes into to an Egalitarian or Individualistic Perspective, the performance of the policy options would be evaluated differently (Fig. 6). Only policy options DH1.5 leads to acceptable results for all Perspectives. The options 'room for the river' and DH1000 give acceptable results for the both the Egalitarian and Hierarchist Perspective. For the Egalitarian Perspective more policy options lead to acceptable results. The current policy options are not enough to achieve targets for the planet indicators; thus, better options need to be explored. For the Individualist Perspective 
only extreme dike raising will reduce the damage to an acceptable level. However, this policy option is very costly. As Individualists do not believe in extreme climate change, they may choose to take the risk and select the DH1000 option. Still, all policy options are much less costly than the potential damages are.

\subsubsection{Low flow policy options}

For the low flow policy options, objectives are achieved using the small vessels and dredging options (Fig. 6). Using small vessels significantly results in an annual navigable time that is 44 times larger than the reference situation with large vessels (current policy). Using medium-sized vessels hardly extends the navigable time. Robust policy options are the use of small vessels and dredging (either small or large scale), as indicated by acceptable indicator values and the small standard deviation. Comparing the results for each climate scenario separately shows that the realisations without climate change and the realisations belonging to the $\mathrm{G}$ climate scenario have more or less the same impact. Analysing the results per 25-year-time period shows that the average non-navigable time per year increases over time under the $\mathrm{Wp}$ scenario. Small-scale dredging meets the targets for the ensemble members of the $\mathrm{G}$ scenario and the scenario without climate change, but not for the Wp scenario in the final 25-year period.

In the case of a shift to an Egalitarian Perspective, there is no urgent need to change the policy, since the current policy scores moderately for the Egalitarian targets. From an Individualistic point of view, current large vessels and medium vessels are not effective. Consequently, the medium vessels are not only less robust due to the environmental conditions (low discharges), but also because of the potential future societal conditions (Perspective change).

\subsection{Development of adaptation pathways}

\subsubsection{Sell-by date of the policy options}

To determine the sell-by date of the flood policy options, the damage per year for each option was considered separately for all ten ensemble members for all three climate scenarios (Fig. 7). For the current Hierarchist Perspective a policy was considered as being no longer durable when the cumulative damage is larger than $2500 \mathrm{M}$ euro. This amount is comparable to the damage due to flooding of four dike rings or two floods in two dike rings. The first four years are not taken into account as the implementation of a policy options was assumed to take four years. A Perspectives change affects the indicators weights: the targets for the Individualist were set at half the values for the Hierarchist and the targets for the Egalitarian were set at twice as large. As shown by the statistics, the sell-by dates of the policies differ a lot for the flood management strategies, not only among the policy options strategies, but also within the ensemble members of the climate scenarios, between the climate scenarios, and among the different Perspectives. The differences caused by the Perspectives are larger, than the differences due to the climate scenarios. Remarkably, the difference between the median values of the sell-by dates for the climate scenarios is quite large (more than ten years) for only five policy options. For the low flow policy options, all these differences are negligible, except for 'small scale dredging' in the Wp scenario. 


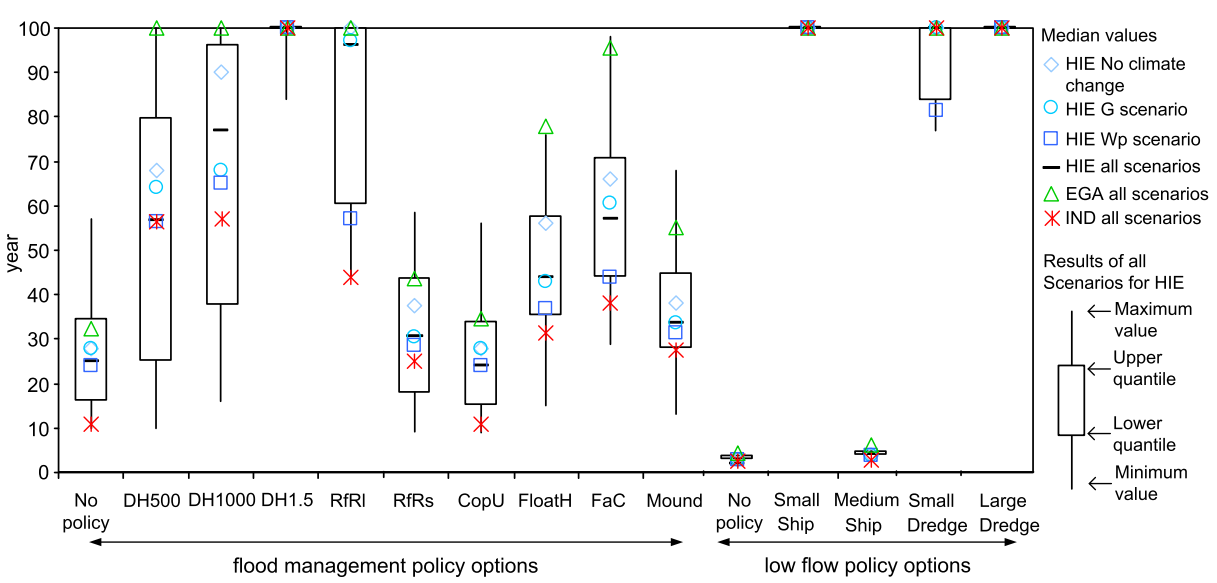

Fig. 7 Box-whisker plots of the sell-by date of the strategies based on the results for all ten realisations of all three climate scenarios in a Hierarchist future (HIE). The median values for each climate scenario separately and for the Egalitarian (EGA) and Individualist (IND) are presented. Left: Sell-by date of flood management policy options using the total damage of $2500 \mathrm{M}$ euro as criterion. Right: Sell-by date of low flow policy options using a criterion of $2 \%$ of non-navigable time for four years in a row. For policy option abbreviations see Table 2

From the current Hierarchist Perspective, raising the dikes to cope with 1.5 times the second highest discharge (DH1.5) and 'room for the river' (RfR) have the longest sell-by date, although in the case of RfR the spread within the realisations is large. For the low flow policy options, $2 \%$ of non-navigable time is taken as the criterion for the sell-by date, which means that for seven days a year it is not possible to use the river for navigation. When this occurs for four years in a row the policy option is assumed to have failed, and is no longer durable. It appears that using large vessels (reference fleet) will soon limit the navigation too much due to problems with the water depth (Fig. 7). With medium-sized vessels the sell-by date is not much better. With small vessels, the sell-by date is 100 years for all climate realisations (i.e. no policy change is needed in any scenario). The same applies for the large-scale dredging. For the small-scale dredging, the average sell-by date is also good, but it is less compared to large-scale dredging (on average, 94 years for all climate scenarios, and 81 years under the most extreme climate scenario (Wp)).

\subsubsection{Low flow management pathways}

The sell-by dates, based on the median values for the current Hierarchist Perspective, were used to develop the adaptation pathways. After an adaptation tipping point (ATP) is reached all other relevant options are considered. Depending on the climate scenario and the Perspective, the ATP is reached earlier or later (as shown in Fig. 7). For the low flow policy options the difference in the sell-by date is rather small, except for policy option of small scale dredging. Figure 8 presents the possible adaptation pathways for low flow management. This adaptation pathways 


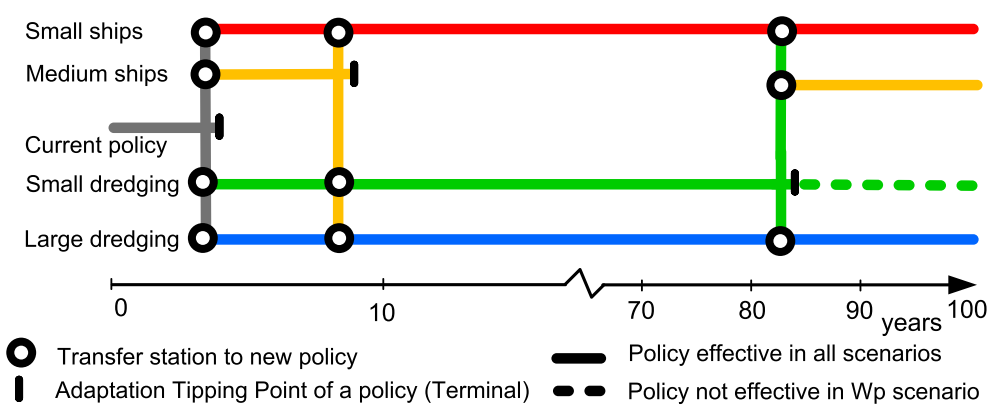

Fig. 8 Adaptation pathway map for low flow management based on the median value for the sell-by date of policy options for all climate realisations in a Hierarchist world. The figure can be read like a map indicating several possible routes to get to a desired point (target) in the future. Similar to a Metro map the circles indicate a transfer station to another policy, only here it is not possible to go back since the lines present a route through time. The blocks indicate a terminal station at which an Adaptation Tipping Point (ATP) is reached. Starting from the current situation, targets are not achieved after four years. Following the grey lines of the current policy, one can see that there are four options which are left after this ATP. With the options small vessels and large scale dredging, targets are achieved for the next 100 years in all climate scenarios and for all perspectives. When medium vessels are chosen, an ATP is soon reached and a shift to one of the other three options is needed to achieve targets (follow the orange lines). With small scale dredging a shift is needed in case of the Wp scenario (follow the solid green lines). In the other scenarios, the targets are achieved for the next 100 years (the dashed line). For policy option abbreviations, see Table 2

map presents different possible routes to get to a desired point (targets) into the future, similar to a Metro map of a city. The map shows the moment of an ATP (terminal station) and the other available policy options, where you can shift to in order to reach your targets (transfer stations). Some routes are not available in the (more severe) Wp climate change scenario (indicated with dashed line). One could argue that following this route to get to your destination is taking a risk, as if the $\mathrm{Wp}$ scenario becomes reality, targets are not achieved anymore, resulting in a need to shift to another policy to reach the destination by taking a transfer station. In such a situation the moment of an ATP occurs much earlier in the Wp scenario than it does in the scenario without climate change and in the $\mathrm{G}$ scenario.

Considering the sell-by date of the current ships (large vessels) it will soon be necessary to shift to one of the other four policy options in all climate realisations. When shifting to small vessels, it is possible to achieve the objectives for the next 100 years in all the climate realisations. The same applies if large-scale dredging is applied. Adaptation to medium-sized vessels will not help much. Within a few years it will be necessary to either shift to another policy option or combine it with the dredging policy options. The small-scale dredging is on average relatively durable, but choosing this option involves taking a risk as this is not effective for the whole 100-year period in all climate scenarios. In the realisations of the most extreme climate scenario the targets will not be achieved after approximately 7786 years (depending on the realisation). It is, however, a flexible policy, since it allows the policy to be changed towards using small or medium-sized vessels or largescale dredging without extra cost. For the low flow policy options, the effect of a 
Perspective change on the sell-by date, and thus the need to shift to another policy, is negligible.

\subsubsection{Flood management pathways}

The total damage accumulates to over 2,500 $\mathrm{M}$ euro within 25 years in all climate scenarios in a Hierarchist future. River improvement policies are thus needed. Several options are open after the first 25 years. We only present the relevant options, meaning options which considerably extend the sell-by date of the policy, and have excluded options which are illogical (for example, it is not logical to first put houses on a mound, and later build floating houses). The pathways are generally based on the median values of the sell-by dates, but if an ATP occurs much sooner in the case of one of the climate scenarios, we indicated this. For the flood management a combination of policy options, which occurs after shifting to another policy, can extend the sell-by date in comparison to the ATP of an individual policy.

The policy options can be divided into flood mitigation and damage mitigation strategies (respectively upper and lower part of the flood pathways in Fig. 9). Flood

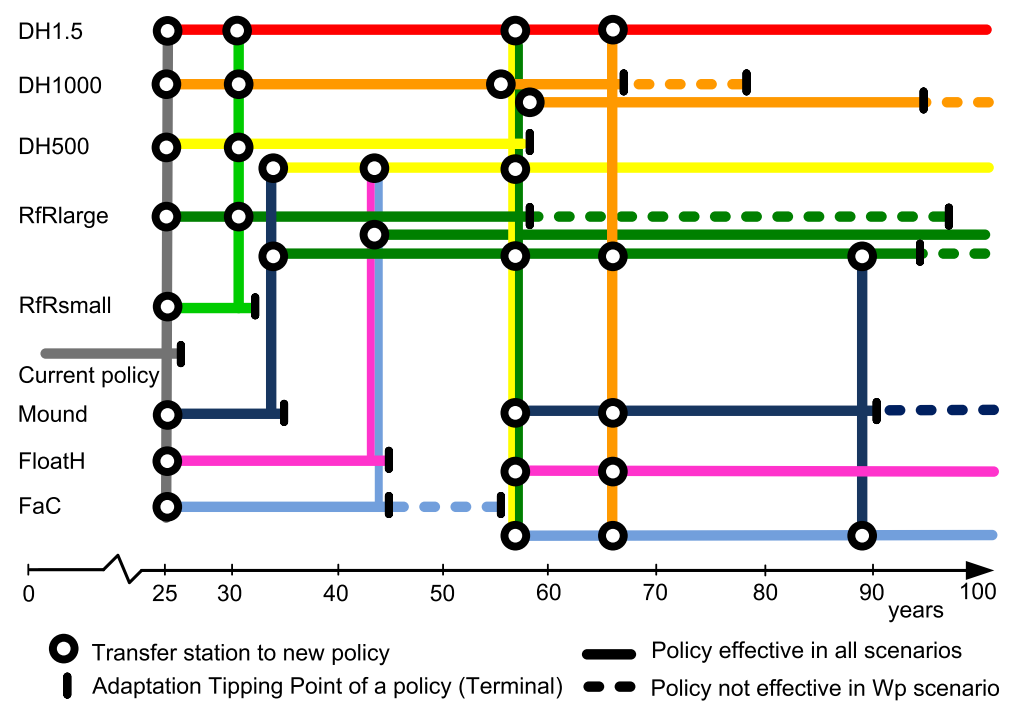

Fig. 9 Adaptation pathway map for flood management based on the median value for the sell-by date of policy options for all climate realisations in a Hierarchist world. The figure can be read similarly to Fig. 8. The map indicates several possible routes to get to a desired point (target) in the future. Similar to a Metro Map the circles indicate a transfer station to another policy. The blocks indicate a terminal station at which an Adaptation Tipping Point (ATP) is reached. Starting from the current policy, targets are not achieved after 25 years. After this ATP several options are left, which also have an ATP. When this occurs depends on the climate scenario and the Perspective as indicated with the sell-by date for these different conditions in Fig. 7). In some situations an ATP is only reached in the Wp scenario. After this point targets are only achieved in the case of the no climate change or G scenario (dashed line). After switching to a new policy, the combined effect is different and often delays the moment of an ATP. In such cases more routes via the same policy are indicated with lines in the same colour. For policy option abbreviations, see Table 2 
mitigation strategies prevent flooding (e.g. dike raising or 'room for the river'), while damage mitigation strategies accept a flood, but diminish or mitigate the flood damage (e.g. floating houses or houses on a mound). In the case that one of the damage mitigation strategies is chosen after 25 years, additional policies are needed after 34-57 years. Raising the dikes up to a design discharge of 1:500 or giving more 'room for the river' after these ATPs is sufficient to achieve the target for the next 95100 years. From the flood mitigation strategies, raising the dikes extremely (DH1.5) would be very effective; in all the considered transient scenarios it will meet the target for the next 100 years. Raising the dikes to cope with the 1:500 and 1:100 discharge is effective for 57 and 77 years respectively (median values of all transient runs), but this may be earlier in the case that the Wp climate change scenario becomes reality. After these points, it is possible to add either more 'room for the river' or to implement one of the damage mitigation options. A combination with 'room for the river' or houses on a mound appears to extend the ATP a lot, but it is ineffective for the most extreme climate scenario (Wp). Thus, taking this route involves taking the risk that the target will not be achieved. With floating houses (FloatH) or additional dikes around the cities $(\mathrm{FaC})$ the target is maintained until almost the end of the century.

\subsection{Evaluation of the policy options and adaptation pathways}

So far, we have analysed the robustness of strategies by determining their performance with targets for sustainability indicators for the three different Perspectives. We determined the sell-by date of the policy options by comparing the results per year with a target for the flood and low flow policy options for each Perspective, which we then used to develop adaptation pathways. The results show that flood mitigation actions are always needed to achieve the targets for the current Hierarchist Perspective, either (1) by raising the dikes extensively (in such a way that they are able to cope with 1.5 times the second highest discharge measured), (2) by combining the dike-raising options with the 'room for the river' measure, or (3) by combining one of the flood mitigation strategies with a damage mitigation measure. The dikeraising options score better in the most extreme climate scenarios than giving 'room for the river', as these strategies include adaptation through raising the dikes to the new design discharge after an event has occurred. This characteristic could be added to the other policy options to improve them. The low flow policy options of small ships and large-scale dredging will meet the targets in all transient scenarios. Choosing small-scale dredging includes taking a risk, as it does not meet the targets in the most extreme climate change realisations.

In addition to the climate scenarios, socio-economic developments may influence the effectiveness of the pathways. Although not explored with the transient scenarios, a potential influence on the pathways could be that some options may not be available in the future. Socio-economic developments may result in additional spatial claims, leaving no space left for strategies such as 'room for the river', which in the end may result in a lock-in situation with no policy options left. Thus, it may be worthwhile to first implement 'room for the river' and later on increase dikes if this would still be necessary, or at least reserve space. 
For all policy options costs, are relatively low (Table 2), compared to the potential damages (Fig. 6). Thus, although some policy options and pathways are muchcheaper than others, from cost/benefit perspective all policy options perform well. Subsequently, implementing a sequence of policy options-which can be considered as an intensification of a strategy or which strengthen each other-would be even cheaper. Examples would be, first implementing small scale and later large scale 'room for the river' or the implementation of a sequence of dike raising options (although the latter should be considered with care, because the initial costs for dike-raising are very high).

Finding robust strategies under changing environmental conditions is already difficult. Increasing their robustness by making the strategies also robust for Perspective change is an extra challenge. In the previous section, this was explored by analysing the performance for Perspective-based targets. Another way of finding Perspective-robust strategies is through evaluating the strategies and pathways descriptively using the core beliefs of a Perspective (see Supplementary Appendix for a view of each Perspective on the policy options) and storylines describing potential futures with Perspective change. Strategies that are acceptable for all Perspectiveseven if this is for a different reason-are more robust (Offermans et al. 2008). For example, 'room for the river' may be preferred by the Egalitarian, because it enhances nature and lowers water levels in the case of peak discharges, while the Hierarchist prefers this strategy, because it lowers the flood risk. Considering the past, it is possible to imagine that the current Hierarchist Perspective in the Waas may change (Offermans 2010). Environmental calamities and increasing societal inequalities could enforce the non-dominant presence of an Egalitarian Perspective to become dominant. Individualists argue the Hierarchical bureaucracy and lack of innovation and technological inventions. A long period of severe drought, wherein typical Hierachist solutions (e.g. water storage and proper distribution), were not sufficient, could increase the popularity of typical Individualistic ways to manage water supply (e.g. market-based innovative solutions such as farmers who re-use water and develop drought resistant crops) (Offermans 2010).

If the Perspective was to change to Egalitarian, 'room for the river' would be more appreciated, because of the impacts on the planet indicators. Both the Hierarchist and the Egalitarian evaluate this policy option well, raising the robustness of this policy. It is thus wise to either first select this option or to save space for it to be implemented later, in case the Perspective changes in the future. The Egalitarian is not in favour of dike-raising, since dikes are unnatural and disturb natural river functions. According to them, trying to control nature is inherently wrong. However, the Egalitarian targets for total damage are achieved with this policy option. Thus, although this policy option is not preferred, it may be implemented with support of this Perspective as part of finding consensus with Hierarchists. In an Egalitarian world, it is more likely that society prefers the small vessels above the large-scale dredging, because of possible ecological impacts and because the latter policy should be implemented each year, which may not seem sustainable. From the policy options considered in the experiment, only 'floating houses' and 'houses on a mound' are preferred strategies for the Individualist. These strategies are, however, inadequate to achieve the Individualist targets. So, either other Individualistic policy options should be explored, or they must shift to Egalitarian or Hierarchist policy options. 


\section{Evaluation of the method}

By applying our approach for a hypothetical case we have learned about the strengths and weaknesses of the approach, which we elaborate in this section. A strength of the method is that the resulting pathways give information on the effectiveness and timing of policy options. In addition, the interactions between the social and water system makes the pathways more realistic. The use of transient scenarios supports the development of pathways by enabling the analysts to assess under which conditions and time span a strategy may fail. Other studies that also presented pathway information-in the sense that they mention either the durability (Kwadijk et al. 2010) or the planning of strategies through time (EA 2009) -first assessed under what sea level rise a strategy may fail and then determined the moment when this occurs by linking the specific value of sea level rise to a scenario assuming a linear change between now and an end-point scenario. However, for strategies needed for coping with extreme events of for example precipitation and discharges, the transient scenarios are a useful tool. Working with the IAMM and transient scenarios increases the knowledge of the system and the potential impact of dynamics through natural variability and the interaction between the water system and society. This feedback was received after using a game setting with policymakers. Water managers and other stakeholders can experience the effects of (the interaction between) water and social events and how this influences the decisionmaking. Different types of uncertainty, as distinguished by Haasnoot et al. (2011), are now included in the analysis for decisions on water management. Natural uncertainty is included through the different realisations of the scenarios. Social uncertainty is now included through the Perspectives method by taking into account different possible futures, individual strategies, and weights to the indicators through different value ranges, enabling the development of robust strategies under changing physical, socio-economic, and societal conditions. The IAMM allows rapid assessment of many transient scenarios. The different parts of the IAMM are completely integrated through the cause-effect relations, which interact in each time step. This enables real dynamic modelling and provides insight into the dynamic part of the system, in contrast with most other IAMs, which often consist of linked submodels (Rotmans and Van Asselt 2001; Schneider and Lane 2005).

The weaknesses of the method are related to the simplifications made. Simplifications are needed when complexity is increasing, such as done in this study by including the water-society interaction and by considering many time-series. The challenge is to capture enough detail and process information by the models to ensure that they perform adequately for analysis and decisionmaking. The simplicity of the response curves may result in underestimation or disappearance of some effects. For a real case study it will be necessary to validate the IAMM, as was argued by Schneider (1997) and executed by Van Vuuren et al. (2011). Hodges and Dewar (1992) and Hodges (1991) discuss uses of unvalidatable models. Our use falls into one of their categories.

In the current case study, we analysed flood and low flow policy options in separate pathways. This was possible because neither pathway influence the other, since the flood reduction policy options had no effect on low flows and vice versa. In integrated water resources management in the real world, different strategies serving different objectives may interfere and affect multiple river services. Furthermore, 
integrated water resources management concerns a larger number of river-related services, leading to multiple targets, that all should be considered in developing water management strategies and associated decisionmaking. This will lead to additional evaluation pathways for e.g. ecology, agriculture, industrial water use, and recreation. Obviously the different pathways will then mutually depend on each other. This will make determining robust strategies and pathways less straightforward. Furthermore, in the real world socio-economic developments will influence the effectiveness of strategies and pathways as well; some policy options may be feasible now but not after several decades. We plan to explore these issues in a subsequent real-world case study.

The influence of Perspective change on the pathways could be further explored, for example by simulating Perspectives with the model through more complex response rules and by including diversity in Perspectives (dominant and non-dominant Perspectives, non-stereotypical Perspectives, and different Perspectives at different levels).

A worthwhile addition to the pathways could be the use of signposts and triggers for deciding when additional or other strategies should be implemented such as done by Dewar et al. (1993), Walker et al. (2001) and Kwakkel et al. (2010), although, it may be difficult to find good triggers for water management. For example, water managers would like to know if climate change is happening because of the potential increase of floods and droughts. However, measuring for example peak discharges as a sign that climate change is happening is very difficult, because of high natural variability and the short time period of measurements (Diermanse et al. 2010).

In spite of its limitations, it seems worthwhile to explore the method further for a real case study. Also validation is needed, in order to assure an appropriate model for decisionmaking on long-term water policy options.

\section{Conclusions}

The objectives of the study presented here were (1) to implement the adaptation pathway approach for sustainable water management with an IAMM and transient scenarios, and (2) to experiment with this implementation to see whether to assess the relevance of such an approach for decisionmaking under uncertainty.

The hypothetical case demonstrated that it is possible to apply the method and to achieve plausible results that could be useful for decisionmaking under uncertainty. With the IAMM and transient scenarios, we explored and evaluated adaptation pathways. A map of adaptation pathways presents not only the feasible policy options, but also when and where they will fail. When a strategy becomes ineffective and thus reaches its Adaptation Tipping Point depends on how the future will unfold in terms climate, socio-economic, and Perspective conditions; the shape of the pathways thus remains the same, but the time span differs. The maps do show that for some strategies this timing does not differ much. Also, more types of uncertainty are taken into account. By using transient scenarios and the iteration in the PSIR chain, the natural variability and dynamics in the water and social system, as well as the interaction between these systems, become more explicit in effect analysis and policy development. This is important for an adaptive approach to cope with uncertainty (Pahl-Wostl 2007). The results show, for example, that climate variability, and 
Perspectives (in terms of targets) may be at least as important for decisionmaking as climate change, especially for the mid- to long-term. Using the IAMM in a workshop setting confirms this conclusion, as the response of users was reactive to the events (caused by climate variability) rather than anticipating future events (climate change). The Perspective-based evaluation has the possibility for ensuring pathways that not only lead to sustainable water management under different possible physical and socio-economic developments, but also under different possible societal futures (perspectives).

The adaptation pathways may support decisionmaking under deep uncertainty. Because of the interaction between the water system and society, the method may even support decisionmaking in the case of persistent problems, which are characterized by a complex interaction of broad societal trends and physical (natural) processes (such as climate change) and the involvement of many stakeholders with different but plausible perspectives (Rotmans 2006).

Acknowledgements We would like to thank the reviewers for their useful comments and suggestions. This paper is a result of the project Perspectives in Integrated Water Resources Management in river deltas. We thank N. Lips (Utrecht University), P. Valkering (ICIS Maastricht), R. van der Brugge, J. Kwadijk (Deltares), and M. van Lieshout (Pantopicon) for their contributions to this project. The project is financed by Deltares and ICIS.

Open Access This article is distributed under the terms of the Creative Commons Attribution Noncommercial License which permits any noncommercial use, distribution, and reproduction in any medium, provided the original author(s) and source are credited.

\section{References}

Agusdinata DB (2008) Exploratory modeling and analysis: a promising method to deal with deep uncertainty. PhD thesis, Delft, Delft University of Technology

Bankes SC (1993) Exploratory modeling for policy analysis. Oper Res 41:435-449

Bigelow JH, Davis PK (2003) Implications for model validation of multiresolution, multiperspective modeling (mrmpm) and exploratory analysis. Tech. Rep. ISBN: 0-8330-3482-0, RAND, Santa Monica

Booij MJ (2003) Determination and integration of appropriate spatial scales for river basin modelling. Hydrol Process 17(13):2581-2598

Buishand TA, Brandsma T (1996) Rainfall generator for the rhine catchment: a feasibility study. Tech. Rep. Technical Report TR-183, KNMI, De Bilt

Carter T, Jones R, Lu X, Bhadwal S, Conde C, Mearns L, ONeill B, Rounsevell M, Zurek M (2007) New assessment methods and the characterisation of future conditions. In: Climate change 2007: impacts, adaptation and vulnerability. contribution of working group II to the 4th assessment report of the intergovernmental panel on climate change. Cambridge University Press, Cambridge

Davis PK, Bigelow J (1998) Experiments in multiresolution modeling. Tech. Rep. Report MR-1004DARPA, RAND, Santa Monica

Davis PK, Bigelow JH (2003) Motivated metamodels. Synthesis of caus-effect reasoning and statistical metamodeling. Tech. Rep. ISBN: 0-8330-3319-0, RAND, Santa Monica

De Bruijn K (2008) Bepalen van schade ten gevolge van overstromingen voor verschillende scenario's en bij verschillende beleidsopties. (determining flood damage for different scenarios and policy options). Tech. Rep. Q4345.00, Deltares, Delft

Delsman J, Veldhuizen A, Snepvangers J (2008) Netherlands hydrological modelling instrument (in Dutch: national hydrological modelling instrument). In: Proceedings of international congress MODFLOW and more: ground water and public policy. Golden, $\mathrm{CO}$

Dewar JA, Builder CH, Hix WM, Levin MH (1993) Assumption-based planning: a planning tool for very uncertain times. Tech. Rep. Report MR-114-A, RAND, Santa Monica 
Diermanse FLM, Kwadijk JCJ, Beckers JVL, Crebas JI (2010) Statistical trend analysis of annual maximum discharges of the rhine and meuse rivers. In: Proceedings of British hydrological society, 3rd international conference. role of hydrology in managing consequences of a changing global environment. xcxbx, http://www.ceg.ncl.ac.uk/bhs2010/. Accessed 19 March 2012

Douglas M (1970) Natural symbols. Barrie and Rockcliff. London, UK

EA (2009) Thames estuary 2100, managing flood risk through London and the thames estuary. Tech. rep., Environment Agency. http:/www.environment-agency.gov.uk/research/ library/consultations/106100.aspx. Accessed 4 May 2011

Guisan A, Zimmermann NE (2000) Predictive habitat distribution models in ecology. Ecol Model 135(2-3):147-186. doi:10.1016/S0304-3800(00)00354-9

Haasnoot M, Van Der Molen DT (2005) Impact of climate change on ecotopes of the rivers rhine and meuse. Arch Hydrobiol Suppl 15:53-61

Haasnoot M, Van der Wolfshaar K (2009) Combining a conceptual framework and a spatial analysis tool, habitat, to support the implementation of river basin management plans. Int J River Basin Management 7:295-311

Haasnoot M, Verkade JS, Bruijn KM (2009) Habitat a spatial analysis tool for environmental impact and damage assessment. In: Hydroinformatics. Concepcion, Chili

Haasnoot M, Middelkoop H, Van Beek E, Van Deursen WPA (2011) A method to develop sustainable water management strategies for an uncertain future. Sust Dev 19(6):369-381. doi:10.1002/sd.438

Hodges JS (1991) Six (or so) things you can do with a bad model. Oper Res 39(3):355-365

Hodges JS, Dewar JA (1992) Is it you or your model talking? A framework for model validation. Tech. Rep. Report R-4114-AF/A/OSD, RAND, Santa Monica

Hoekstra AY (1998) Perspectives on water: an integrated model-based exploration of the future. International Books, Utrecht, The Netherlands

Kleijnen JPC, Sargent RG (2000) A methodology for fitting and validating metamodels in simulation. Eur J Oper Res 120(1):14-29

Kok M (2005) Standaardmethode 2005. schade en slachtoffers als gevolg van overstromingen. (Standard method 2005. Damage and casualties caused by flooding). Tech. Rep. Report 999.10., HKV, Lelystad

Kwadijk JCJ, Haasnoot M, Mulder J, Hoogvliet M, Jeuken A, Krogt R, Oostrom N, Schelfhout H, Velzen E, Waveren H, Wit M (2010) Using adaptation tipping points to prepare for climate change and sea level rise: a case study in the Netherlands. WIREs Climate Change. doi:10.1002/wcc. 64

Kwakkel JH, Walker WE, Marchau VAWJ (2010) Adaptive airport strategic planning. EJTIR 10(3):249-273

Lempert RJ, Schlesinger ME (2000) Robust strategies for abating climate change. Clim Change 45:387-401. doi:10.1023/a:1005698407365

Lenderink G, Buishand TA, Van Deursen WPA (2007) Estimates of future discharges of the river rhine using two scenario methodologies: direct versus delta approach. Hydrol Earth Syst Sci 11(3):1145-1159

Middelkoop H, Van Deursen W (1999) The impact of climate change on inland navigation on the river Rhine. Tech. rep., Rijkswaterstaat-RIZA, Lelystad

Middelkoop H, Van Asselt MBA, Van’t Klooster SA, Van Deursen WPA, Kwadijk JCJ, Buiteveld $\mathrm{H}$ (2004) Perspectives on flood management in the Rhine and meuse rivers. River Res Applic 20:327-342

Morgan MG, Dowlatabadi H (1996) Learning from integrated assessment of climate change. Clim Change 34:337-368. doi:10.1007/BF00139297

OECD (1993) Environmental indicators: basis concepts and terminology. Indicators for use in environmental performances reviews. Paris, France

Offermans A (2010) Learning from the past: the interaction of the social system and the water system in The Netherlands. In: Conference on the human dimensions of global environmental change. Berlin, http://www.berlinconference.org/2010/. 10 October 2010

Offermans A, Haasnoot M, Van Beek E, Middelkoop H (2008) Advies van de deltacommissie vergt breder perspectief. (Advice of the delta committee calls for wider perspective). H2O 20:36-40

Offermans A, Haasnoot M, Valkering P (2011) A method to explore social response for sustainable water management strategies under changing conditions. Sust Dev 19(5):312-324. doi:10.1002/sd.439. Accessed 19 March 2012

Pahl-Wostl C (2007) Transitions towards adaptive management of water facing climate and global change. Water Res Manage 21:49-30. doi:10.1007/s11269-006-9040-4 
Rotmans J (2006) Tools for integrated sustainability assessment: a two-track approach. IAJ 6(4): $35-37$

Rotmans J, De Vries HJM (1997) Perspectives on global change: the TARGETS approach. Cambridge University Press, Cambridge

Rotmans J, Van Asselt MBA (1996) Integrated assessment: a growing child on its way to maturity. Clim Change 34:327-336

Rotmans J, Van Asselt MBA (2001) Uncertainty management in integrated assessment modeling: towards a pluralistic approach. Environ Monit Assess 69(2):101-130

Schneider S, Lane J (2005) Integrated assessment modeling of global climate change: much has been learned—still a long and bumpy road ahead. IAJ 5(1):41-75

Schneider SH (1997) Integrated assessment modeling of global climate change: transparent rational tool for policy making or opaque screen hiding value-laden assumptions? Env Model Assess 2(4):229-249

Te Linde AH (2007) Effect of climate change on the discharge of the rivers rhine and meuse. Applying the knmi 2006 scenarios using the hbv model. Tech. Rep. Q4286, Delft Hydraulics, Delft, The Netherlands

Te Linde AH, Aerts JCJH, Bakker AMR, Kwadijk JCJ (2010) Simulating low-probability peak discharges for the Rhine basin using resampled climate modeling data. Water Resour Res 46(W03512):21. doi:10.1029/2009WR007707

Thompson M, Ellis R, Wildavsky A (1990) Cultural theory. Westview Press, Boulder

Van Asselt MBA (2000) Perspectives on uncertainty and risk: the PRIMA approach to decision support. Kluwer Academic Publishers, Dordrecht

Van Asselt MBA, Rotmans J (1997) Uncertainties in perspective. In: Perspectives on global change: the TARGETS approach. Cambridge University Press, Cambridge

Van Asselt MBA, Rotmans J (2002) Uncertainty in integrated assessment modelling from positivism to pluralism. Clim Change 54(1):75-105

Van den Hurk B, Klein Tank A, Lenderink G, Van Ulden A, Van Oldenborgh G, Katsman C, Van den Brink H, Keller F, Bessembinder J, Burgers G, Komen G, Hazeleger W, Drijfhout S (2007) New climate change scenarios for The Netherlands. Water Sci Technol 56:27-33

Van der Brugge R, Rotmans J, Loorbach D (2005) The transition in Dutch water management. Reg Environ Change 5(4):164-176

Van der Heijden K (1996) Scenarios the art of strategic conversation. John Wiley and Sons, Vol Chichester, UK

Van der Sluijs J (2002) Integrated assessment. Wiley, pp 250-253

Van Deursen W (1995) Geographical information systems and dynamic models. PhD thesis, Utrecht University. www.carthago.nl, nGS Publication 190

Van Grol R, Walker WE, Rahman A, de Jong G (2006) Using a metamodel to analyze sustainable transport policies for europe: the SUMMA project's Fast Simple Model. In: EURO 2006, 21st European conference on operational research. Iceland, 2-5 July 2006

Van Velzen E (2008) Basisinformatie voor de kengetallen kosten-batenanalyse wv21 (information for the cost-benefit analysis of water safety 21st century). Tech. Rep. Q4558.31, Deltares, Delft

Van Vuuren D, Lowe J, Stehfest E, Gohar L, Hof A, Hope C, Warren R, Meinshausen M, Plattner GK (2011) How well do integrated assessment models simulate climate change? Clim Change 104:255-285

Vermulst JAPH, Kroon T, de Lange WJ (1998) Modelling the hydrology of The Netherlands on a nation wide scale. In: Wheater $\mathrm{H}$, Kirby $\mathrm{C}$ (eds) Hydrology in a changing environment: proceedings of the British hydrological society. John Wiley and Sons, Exeter

Walker WE, Rahman SA, Cave J (2001) Adaptive policies, policy analysis, and policymaking. Eur J Oper Res 128:282-289

Winkler J, Thornsbury S, Artavia M, Chmielewski FM, Kirschke D, Lee S, Liszewska M, Loveridge S, Tan PN, Zhong S, Andresen J, Black J, Kurlus R, Nizalov D, Olynk N, Ustrnul Z, Zavalloni C, Bisanz J, Bujdosa G, Fusina L, Henniges Y, Hilsendegen P, Lar K, Malarzewski L, Moeller T, Murmylo R, Niedzwiedz T, Nizalova O, Prawiranata H, Rothwell N, van Ravensway J, von Witzke H, Woods M (2010) A conceptual framework for multi-regional climate change assessments for international market systems with long-term investments. Clim Change 103:445470. doi:10.1007/s10584-009-9781-1

Yohe G (1990) Imbedding dynamic responses with imperfect information into static portraits of the regional impact of climate change. Presented at: International workshop on the natural resource and economic implications of global climate change, Interlaken (Switzerland). http://www.osti.gov/energycitations/servlets/purl/6147467-tHoU3E/6147467.pdf. Accessed 5-9 November 1990 